\title{
OR competences: the demands of problem structuring methods
}

\author{
Richard John Ormerod
}

Received: 23 April 2013/Accepted: 25 October 2013/Published online: 4 December 2013

(C) Springer-Verlag Berlin Heidelberg and EURO - The Association of European Operational Research Societies 2013

\begin{abstract}
OR interventions involve the deployment of three core competences: (1) conducting analysis, (2) managing the process of intervention, and (3) understanding context. The nature of these competences is reasonably well understood in terms of traditional interventions but problem structuring methods (PSMs) make additional demands on practitioners. PSMs are designed to help the OR consultant structure an intervention in which actors relevant to the situation engage in interpreting the context, do some qualitative analysis, debate the issues, and agree some future actions. The OR consultant is required to master the methods, design the intervention, facilitate the set pieces such as workshops, and manage the process overall. The paper considers the burgeoning literature on the competences required to deploy PSMs. It is concluded that these competences can be considered under the same broad headings as those for traditional OR, but the skills and the process of obtaining them make new demands. An enhanced schema of OR competence is developed and its application in education and practice is suggested.
\end{abstract}

Keywords OR competence $\cdot$ Problem structuring methods $\cdot$ Process of OR - Critical pragmatism - Transformation competence perspective

\section{Introduction}

On entering academia I started to write about my experience of conducting OR interventions, particularly those involving 'soft OR', now referred to as problem structuring methods (PSMs) (Rosenhead 1996). Initially this took the form of case studies (see for instance, Ormerod 1995, 1996a, b, 1997a). Reflecting on these case

R. J. Ormerod $(\bowtie)$

University of Warwick, Coventry, UK

e-mail: richard@rormerod.freeserve.co.uk 
studies, noting all the factors that have to be taken into account, I concluded that two factors mattered above all else, the transformation to be achieved and the competences to be deployed (Ormerod 1997b). This conclusion gave rise to the transformation competence perspective (TCP) (Ormerod 2008a). This paper will address the competence aspect, using as a focus the conceptual representation of competence found in the burgeoning PSM literature. The approach is similar in orientation to that taken by Quinn and Rohrbaugh (1983) in their analysis of effectiveness criteria.

\subsection{OR practice and change}

I take it that OR is defined by its practice and that OR practice is essentially concerned with conducting interventions to help decision-makers define options and choose between (Ormerod 2010d). The nature of OR competence is of fundamental importance for OR. It is on the basis of their competence that OR consultants can offer their services to clients and differentiate themselves from other purveyors of professional assistance (Parsons 1939, 1952; Larson 1977; Freidson 1986; Abbott 1988). Clients develop an expectation that OR consultants will have certain competences; at the same time, OR consultants develop a view as to what these client expectations are likely to be. OR competence is not a static concept; it changes with each new assignment when something is learnt and something is forgotten. This change is individual to the consultants involved, but the cumulative effect is change in the nature of OR. Sometimes major changes can be identified. For instance, in the 1960s linear programming was widely adopted, greatly increasing the potential for mathematical modelling. In this paper, the new opportunities afforded by PSMs and the demands they make on consultants and lecturers are examined. In some respects this can be likened to the introduction of mathematical programming, but each change has its unique characteristics. In this case, the main change is in the role of the consultant who becomes a process designer and facilitator rather than an investigator and solution provider. PSMs include qualitative as well as quantitative analysis, involve participation and group work, and require close attention to be paid to the management and design of the process of intervention.

The engagement of practitioners in new activities in the field presents academics with new challenges in the development, testing, and teaching of the new approaches; this requires the academic to develop his or her own competence. However, it is conceptually clearer to consider that the competences of practitioners and academics are distinct (although they may well be embodied in the same person, the academic practitioner) (Ormerod 2010c). This paper will consider the competences required for OR practice rather than for academic research and teaching. The purpose of the paper was to examine the new demands created by PSMs and elaborate a schema of OR competences to inform both teaching and practice. Quinn and Rohrbaugh (1983, p. 365) asked the question, 'How do individual theorists and researchers actually think about the construct of [organizational] effectiveness?' The question addressed here is: how do individual theorists 
and researchers actually think about the construct of OR competence as displayed in the PSM literature?

\subsection{OR competences}

A number of authors have addressed the subject of OR competence. Boothroyd attempted to describe OR practice in a realistic way (Boothroyd 1978; see also Ormerod 2010a). Keys (2006) has drawn on sociological theories to examine how competences are developed. Ulrich has approached the subject from a broader and deeper perspective: broader in that he considers all professional practice, not just OR; deeper in that he argues at the philosophical level (Ulrich 1994, 2001, 2011a, b, 2012). Murphy (2001, 2005a, b, c) approaches the issue of competence from the way in which modelling expertise is developed within industrial sectors. My own approach has been to take a resource-based view (Prahalad and Hamel 1990) to derive the core competences of OR from my experience as an OR consultant (Ormerod 2002).

\subsection{Development of PSM competence}

In the 1990s, the teaching of 'soft OR' (or PSMs) presented OR lecturers with a major new challenge. Two interlinked questions needed to be addressed: what aspects of 'soft OR' or PSMs can be addressed within the confines of an academic course; and what form should the teaching/learning take. In other words, lecturers needed to understand the new competences required and decide whether or how they could be introduced in existing courses. A number of papers have directly reported on the experience of teaching soft OR and PSMs (see for instance, Ackermann 2011; Andersen et al. 2006; Hindle 2011; Mingers and Rosenhead 2011).

Gaining realistic experience in the classroom is problematic. Although some aspects can be learnt on courses, it is in the field that practitioners hone their skills; learning-by-doing is particularly important in the case of PSMs. The reported experience of using PSMs in practice is therefore highly relevant. Reports of my own experiences are by now quite extensive (Ormerod 1995, 1996a, b, 1997a, 1998a, b, 1999, 2001a, 2005; Pauley and Ormerod 1998) and many other reports of applications have been identified in the literature review by Mingers and White (2010).

\subsection{The revised OR competence schema and its application}

In the light of what can be learnt from the PSM literature, an updated OR competence schema is derived (Fig. 4). It is intended that the updated schema finds application in practice, but it may also be considered relevant for those teaching OR. The schema remains tentative and open to improvement and change. 


\section{The core competences required for $\mathrm{OR}$ practice}

\subsection{The OR competence model}

Competence is what any professional has to offer potential clients: the existence of any particular profession depends on developing and maintaining its distinctive competence relative to other sources of help or advice. The competence of OR lies in the ability of its practitioners to help clients make use of quantitative and qualitative analysis in their decision-making. But what are the core competences that allow OR to provide such a valued and distinctive service? Eden and Ackermann put the question for any organisation thus:

The basic starting question that must be answered by an organisation is, 'What do, or can we do, exceptionally well that our customers perceive adds more value than alternative providers?' An organisation stays alive by providing 'value' to a stakeholder-base. ... This value is derived from a combination of stakeholder demand and the distinctive competencies of the supplying organisation. 'Distinctiveness' here means some measure of difference, of being able to offer to the 'customers' something that no other competitor can (Eden and Ackermann 2000, p. 13).

I tried to apply the question posed by Eden and Ackerman for any business to the specific case of the OR profession (Ormerod 2002). To do so, I turned to the approach suggested by Prahalad and Hamel (1990). The resulting competence model (see Fig. 1) depicts three core competences, conducting analysis, managing process and understanding context, which are embedded in two core products characterized as smart bits and helpful ways; these are delivered as three client services, smart bits (algorithms and models), helpful ways (investigations) and a third, which combines elements of the other two to address significant societal issues, things that matter (Ormerod 1997c, 1998b). The core competences are developed and maintained in individual strands and collective webs of practice of the OR consultants (Corbett and Van Wassenhove 1993; Ormerod 2002).

The view that there are three broad competences (analytical, process, context), described here as core, is a personal view based on experience. The competence model is a structured collection of hypotheses that cannot be simply validated; however, some support can be sought in the views of other commentators. Few would doubt that analysis (including model building) is a core competence. The importance of process was brought to the fore by Boothroyd (1978) and developed in the debates about 'soft OR' and PSMs. Mitchell (1993 p. 10) suggests that one of the 'skills' required in OR engagement is an understanding of the technical, social, and cultural context in which the problem is set. Murphy, in a wide ranging review published as a set of three papers (Murphy 2005a, b, c), states that 'expertise in the context of OR practice consists of technical knowledge, institutional knowledge, and procedures and heuristics for bringing that knowledge to bear on the problem at hand and organizational issues' (Murphy 2005b p. 313). Murphy's depiction of 'expertise' almost exactly mirrors that of 'competence' adopted here. Whether described as competences, expertise or skills, 'analysis or model building', 'process design and management', and 'understanding 
Client Service Offerings: Smart Bits, Helpful Ways, Things that Matter (policy analysis)

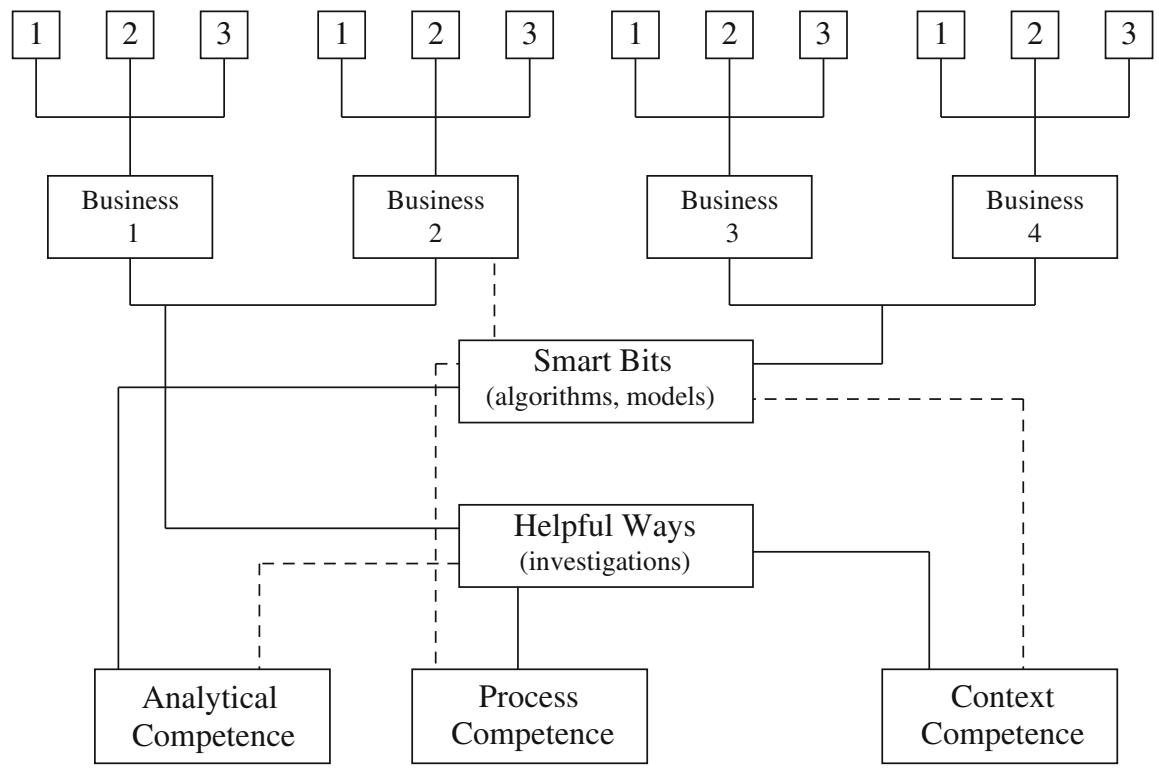

Fig. 1 The OR core competence model (Ormerod 2002)

context' seem to be considered important by other commentators; there is more evidence of this in the literature reviewed later. The relative importance of each competence in any particular intervention will vary. For instance, in 'smart bit' interventions analysis will clearly be of key importance, albeit supported by a process of intervention and an understanding of context; for 'helpful ways' interventions process design and management will be key; and so on. Figure 2 illustrates likely differences in emphasis.

\subsection{The competence schema}

To provide a context for more detailed discussion about these important core competences, I have previously used an expanded depiction of core competences in the form of a high-level schema shown in Fig. 3. Whereas the three core competences are fairly well supported in the literature as indicated above, the subcategories of the schema shown in Fig. 3 are much more tentative. I have nevertheless taken the schema as a starting point and used it to provide the context for papers on two sub-categories of the schema, Rational Inference and Rational Choice (Ormerod 2010b, d). The sub-category Rational Choice includes both hard and soft analysis. Problem Structuring is identified as a separate sub-category and although I have not elaborated it specifically for the schema, much has been written on the subject (see for instance, Boothroyd 1978; Woolley and Pidd 1981; Rosenhead and Mingers 2001). The sub-category Facilitation recognizes the inclusion of 'soft' skills and again I have not elaborated it further but plenty of 


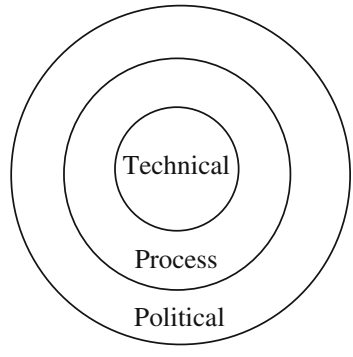

(a) Smart Bits (algorithms, models)

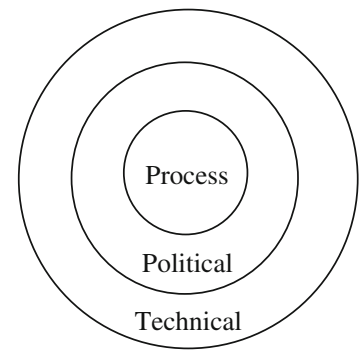

(b) Helpful Ways (investigations)

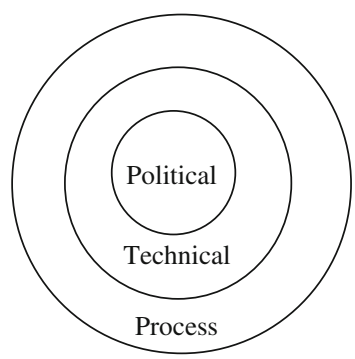

(c) Things That Matter (policy analysis)

Fig. 2 Archetypes of OR intervention (Ormerod 2008b)

others have addressed the subject (see for instance, Phillips and Phillips 1993; Ackermann 1996; Franco and Montibeller 2010). TCP is a contribution to the subcategory Intervention Design (Ormerod 2008a). Jackson's creative holism (Jackson 2003) and Mingers' multi-paradigm multimethodology (Mingers 1997) are similar in intent. Thus, the hooks are already there in the schema for the inclusion of PSMs in their several aspects. The aim here was to revisit the schema in the light of the burgeoning literature on the development and deployment of PSM competences.

\section{The motivation for developing and using PSMs}

As long ago as 1938 Dewey, one of the originators of American pragmatism (Ormerod 2006), recognized the practical significance of structuring problems:

A problem represents the partial transformation by inquiry of a problematic situation into a determinate situation. It is a familiar and significant saying that a problem well put is half-solved. To find out what the problem and problems are which a problematic situation presents to be inquired into, is to be well along in inquiry. To mistake the problem involved is to cause subsequent inquiry to be irrelevant or to go astray. Without a problem, there is blind groping in the dark. The way in which the problem is conceived decides what specific suggestions are entertained and which are dismissed; what data are selected and which rejected; it is the criterion for relevancy and irrelevancy for hypotheses and conceptual structures. (Dewey 1938b, p. 108; italics in the original).

Similar sentiments have been expressed in the OR literature. The originators of PSMs provided methods which have been used to structure problematic situations: Checkland (1981) set out to formulate a better way of conceptualizing messy systems of human activity; Friend and Hickling (1987) set out to develop an approach to strategic choice based on the way that such decisions are discussed and resolved in practice. Eden (1988) set out to develop a way of engaging senior managers in discussions on strategy. Rosenhead in his seminal book, Rational 


\section{Core Competences of OR}

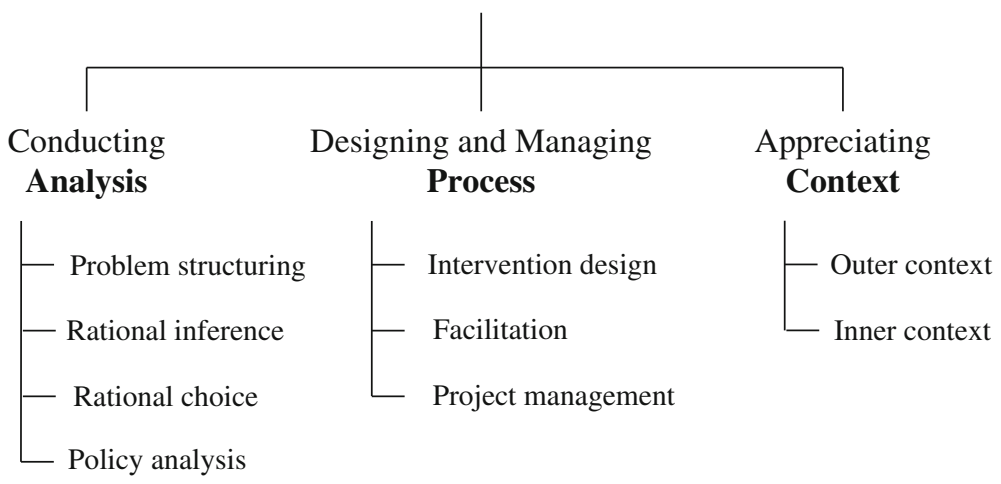

Fig. 3 The initial schema for the core competences of OR practice

Analysis for a Problematic World: Problem Structuring Methods for Complexity, Uncertainty and Conflict, made available in accessible form the ideas of these and other pioneers. He proclaimed that they collectively constituted a new and distinctively British contribution to the art and craft of structuring problems (Rosenhead 1989, p. xiii).

3.1 A new paradigm for wicked, messy problem situations?

Comparing PSMs with what he refers to as the 'dominant paradigm', Rosenhead suggests the following characteristics of the 'new paradigm':

1. Non-optimizing; seeks alternative solutions which are acceptable on separate dimensions without trade-offs.

2. Reduced data demands, achieved by greater integration of hard and soft data with social judgements.

3. Simplicity and transparency, aimed at clarifying the terms of conflict.

4. Conceptualizes people as active subjects.

5. Facilitates planning from the bottom up.

6. Accepts uncertainty, and aims to keep options open for later resolution. (Rosenhead 1989, p. 12).

In a second edition of the book edited by Rosenhead and Mingers the raison d'être of PSMs is explained as follows:

Problem structuring methods ... accept as a fact that the most demanding and troubling task in formative decision situations is to decide what the problem is. There are too many factors; many of the relationships between them unclear or in dispute; the most important do not reduce naturally to quantified form; different stakeholders have different priorities. PSMs use models (often in the plural, and with little or no quantification) to help (mostly) group decision-making-since it is rare for such issues to be resolved by single decision-makers. The model 
representations are used to provide enough structure that those who must take responsibility for the consequences of the choices which are made, do so on a coherent basis and with sufficient confidence to make the necessary commitments. (Rosenhead and Mingers 2001, p. 1; italics in the original).

Rosenhead and Mingers describe the RAND Corporation's attempt to apply their conventional (cause-effect modelling and optimizing) approach to the dilemmas of big city government (New York). 'The results were very mixed. Success and implementation depended very much on the context. Traditional methods worked well to the extent that the relevant city agency was structured as a quasi-military hierarchy; few of its staff were analytically sophisticated; the agency performed a well defined task whose repetition generated reliable data suitable for quantitative manipulation; and priorities between alternative objectives commanded almost universal consensus. All these features were in place for RAND's extensive work with the fire service. Diametrically opposed conditions held for the city's public health administration, and there RAND encountered comprehensive failure' (Rosenhead and Mingers 2001, p. 4). Rosenhead and Mingers observe that this recognition of a dichotomy of problem situations had been reached independently by many observers and commentators: Ackoff (1979a) contrasts messes and problems; Rittel contrasts wicked versus tame problems (Rittel and Webber 1973); Schön (1983) contrasts the swamp and the high ground; Jackson and Keys (1984) contrast unitary, pluralistic and coercive problem contexts.

\subsection{Experience with PSM deployment in practice}

I first came into contact with PSMs in the early 1980s when as a corporate strategist I wanted to characterize uncertainty. I had read an account of the strategic choice approach (SCA) (Friend and Hickling 1987) and the characterization it offered met my need (Ormerod 1983). However, it was not until as a consultant I was designing a participative process for the UK supermarket chain Sainsbury's in the late 1980s that I considered using soft methods in an intervention. Having up to that point conducted consulting interventions along relatively conventional lines, I perceived a need for something different in this case; something that was more creative and participative; a process that helped the company 'envision a future and make it happen' (Ackoff 1974, 1979b). For me participation was the key. Participation would enable a shared understanding of the situation to be developed; but more importantly, by engaging those who would be responsible for the implementation of the strategy, it would ensure ownership of the decisions and commitment to implement them. I concluded that the process I had in mind could be supported by the use of several 'soft' OR methods, or in other words PSMs. The impact of the project from the client's perspective was summarized by David Quarmby, the joint managing director, reflecting on the intervention 5 years later:

The approach introduced a more open and participative method of decisionmaking. Old constraints were discarded and new ideas were explored creatively. The exercise began to shape how we saw the management of the supply chain: we have now reorganized responsibilities and reshaped our 
decision-making mechanisms to reflect the full potential of these systems to add real value to the business. There is no doubt that this strategy has been a critical foundation stone in driving our competitive advantage in the past 5 years not only in the benefits the systems have delivered but also in the changes in attitude and involvement by line management. By this I mean, first, that the managers now own the vision in IT terms, in terms of changes to the way the business can be run, and in terms of the substantive hard benefits that can be and have been delivered. Second, the line managers have had their awareness of the business process raised in terms of the value to the customer and managing business more effectively. Third, we learnt a lot from the way the strategy was developed. It was a real education for management. It opened their eyes to new and innovative ways of understanding the business, developing IT solutions and making good decisions (Quoted in Ormerod 1996a, p. 123).

Following the success of the Sainsbury's project (Ormerod 1995, 1996a), I carried out a series of interventions that was built on the experience gained (see for instance, Ormerod 1996b, 1998a, 1999, 2005). The client organizations (for instance, supermarket chains, mining corporations, and utility providers) were hierarchical with clear, largely uncontested, objectives and priorities. However, soft methods were chosen for the very reason that they could help breakdown hierarchical thinking and departmental division. The idea was to encourage creative interdisciplinary (interdepartmental) thinking among those closely involved in managing operations; in order to take advantage of the new capabilities offered by information technology, fresh thinking was required. This experience does not contradict Rosenhead and Mingers' conclusion that conventional approaches tend to be difficult to apply in ill-defined situations; rather it adds the conclusion that perhaps surprisingly, soft methods may be applicable in hierarchical organizations with clear objectives and decision-making procedures where different points of view need to be reconciled.

\subsection{Participation, facilitation, negotiation, and group processes}

Using soft methods in practice, I placed the emphasis on participation, ownership and commitment. Rouwette et al. (2009) rather similarly emphasize communication, consensus and commitment. Eden and Ackerman (2006) place the emphasis on negotiation, facilitation and group processes. They suggest that the various soft methods have certain characteristics in common: (1) they use models as transitional objects (to facilitate negotiation and agreement and allow analysis); (2) they increase the overall productivity of group processes (better agreements that are more likely to be implemented; manages rather than reduces complexity; solving the right problem; ensuring procedural justice and rationality); (3) they pay attention to the facilitation of effective group processes; and (4) they appreciate the significance of facilitation skills in enabling effective model building, and reaching agreement. All seem to agree that soft methods bring a new dimension to OR's consulting offer. It follows that OR competences have had to evolve and extend. 


\section{The demand for soft problem structuring skills}

The ability to structure problems is a competence required by all managers: even without the use of specific PSMs; structuring a problematic (messy, wicked, etc) situation is something a manager has to do to decide how to act. Decision-makers may make their own mind up or they may turn to a consultant to discuss the matter. Such 'conversations' are crucial as they help in building trust and may lead to new or continued assignments. These conversations become more complex when it is apparent that it is not enough to talk with a single decision-maker; a number of others with different agendas and different perspectives might need to be involved. In offering to help a client structure a problematic situation with the use of PSMs, one is potentially embarking on a more inclusive, transparent, reflective process. Is there any evidence that the skills to do this are recognized as such by practitioners?

\subsection{Recruiting and survey data}

In the UK, the Government Operational Research Service (GORS) supports and champions OR across government employing around 400 analysts. For recruitment purposes, it lists the OR competences it is seeking, including 'defining aims and objectives' and 'problem structuring'; both could involve the use of PSMs (UK Government Operational Research Service (GORS), 2013). In a content analysis of OR recruitment advertising, Sodhi and Son (2010) identify problem solving, communication, interpersonal skills, and team-related skills, as requirements. In a survey of INFORMS members conducted by Liberatore and Luo (2013), the requirement for soft skills is considered explicitly. Table 1 displays the top four quantitative skills and the top four soft skills. Among INFORM members, there is clearly a recognition of the importance of problem recognition and formulation.

\subsection{Evaluation research}

There are now a large number of published cases of PSMs being applied (Mingers and White 2010). These cases have been drawn on by researchers to marry theory and practice to determine how to characterize soft OR skills and evaluate their use in interventions. Checkland (1985, p. 758) suggests that applications of soft systems methodology (SSM) should be scrutinized from the perspective of a (set of linked ideas in a) framework applied using a methodology to explore an area of concern. The appropriateness of this so-called FMA perspective has been the subject of much debate. The subject of evaluation was reinvigorated by Eden's examination of the

Table 1 The top four skills required by OR workers according to INFORMS members (Liberatore and Luo 2013)

\begin{tabular}{lll}
\hline Rank & Quantitative skills & Soft skills \\
\hline 1 & Optimization & Problem formulation \\
2 & Decision analysis & Problem recognition \\
3 & Simulation & Communication \\
4 & Programming & Business knowledge
\end{tabular}


evaluation of group decision support systems (GDSS) and the subsequent discussion (Eden 1995; Eden and Ackermann 1996; Finlay 1998). The discussion centred on the appropriateness of positivist and interpretivist research designs for the evaluation.

In the Sainsbury's case, I received encouraging feedback from those involved, but the question remained: was this just the participants' warm response to having a lot of attention paid to them or could the consultant and participant time and cost be justified by the results? The clients, who were board members, had no doubts: the management development of the participants alone was justification enough. However, I felt more tangible evidence should be sought (and I was curious), so I returned after 5 years had elapsed to see how they had got on with the 5-year strategy they had devised during the project. As the project had been a commercial exercise and implementation had been based on estimated costs, benefits and timings, it was possible to use these as a basis for comparison to evaluate the outcomes (Ormerod 1996a). This remains an unusual exercise as 'hard' evaluations are generally not thought appropriate for 'soft' interventions even though such demonstrations of hard value would be attractive to clients (Westcombe et al. 2006). In later cases short participant questionnaires were used (Ormerod 1996b, 1998a). As a result of these attempts to evaluate soft OR interventions, I concluded that a simple evaluation should pay attention to 'the doers' (the consultants), 'the done for' (the clients), 'the done with' (the participants), 'the done to' (those interviewed), and 'the done without' (those not involved but affected) (Ormerod 2001b).

White (2006) critically reviewed the evaluation literature concluding that positivist approaches are generally inappropriate, but interpretive approaches tend to focus on a variety of different aspects of PSMs and do not reach any conclusion as to what was achieved. He argues that interpretive approaches lack an appropriate theoretical underpinning, and suggests that an evaluation should be a systematic and aggregative study of the links between action, outcomes and context. Describing an example of evaluation involving reflection, interviews and group discussions, White notes the importance to those involved of participation and facilitation, and the consequent impact on the formation of social networks, changes in attitudes, and adjustments to power relationships (p. 849).

Franco (2007), reporting on the evaluation of an application of a PSM in a multiorganisational setting, summarizes the products of PSM interventions under six headings: (1) model and problem structure (models as transitional objects, negotiating devices); (2) accommodations of multiple positions (participants may be required to adjust their positions and/or expectations to take into consideration the possible objectives and strategies of others); (3) shift in power relations (accommodations between actors might also require coalition forming); (4) increased understanding and learning (participants gain an increased understanding of the issues of common concern, of organizational processes and cultures, and of others' beliefs and values); (5) ownership of problem structure and of consequence of planned actions (active participation produces strong ownership of the problem formulation, as well as acceptance of responsibility for the consequences of the actions taken); and (6) partial commitments (the accommodation, increased 
understanding, and ownership achieved takes the form of a set of partial commitments based on the notion that the only way to make progress in swamp conditions is by adopting an incremental approach and thus working on a less comprehensive solution).

Rouwette et al. (2009) draw on two theories from social psychology, the theory of planned behaviour and the dual process theory of persuasion, to develop a conceptual framework for evaluation. The framework combines three domains: (1) context (organisation, problem); (2) mechanisms (modelling, facilitation, communication); and (3) outcomes (mental model refinement, consensus, commitment, system changes). Drawing on the framework, Rouwette (2011) evaluates a facilitated modelling application using questionnaires and semi-structured interviews.

Champion and Wilson (2010) derive contingency factors for PSM validation drawing on the validation used for decision support systems, their own experience of using PSMs, and the views of PSM experts. They identify two groups of factors under the headings 'decision and outcome' and 'people'. The latter group consists of three contingency factors: systems builder competence; politics and personalities of those involved; and experience of stakeholders. Bell and Morse (2013) address the evaluation of group dynamics, individual behaviours and facilitation as experienced by the facilitators themselves and by those being facilitated. Their analysis reinforces the crucial role of facilitation. Midgley et al. (2013) propose an evaluation model consisting of four necessary foci: the use of a particular method (or set of methods) in a context for particular purposes, giving rise to outcomes. These foci need to be 'interrelated in the context of a specific reflection on the use of a method' (p. 146).

In terms of the OR competence schema, the research into the evaluation of PSMs places the emphasis on facilitation, the choice of appropriate methods, and the design of the intervention and group formation to ensure engaged participation. Thus, in comparison with the quantitative modelling of traditional OR more emphasis is placed on the middle leg of the schema, the designing and managing of process (see Fig. 3). In addition, the evaluation literature delves more deeply into the characteristics of PSM interventions emphasizing the importance of inter alia the effect on social networks, changes in attitudes and changes in the power relationships. Thus, the importance of consultants gaining an appreciation of the context (the third leg of the schema, see Fig. 3) is brought more sharply into focus.

\section{Developing competence in the use of PSMs}

\subsection{Becoming professionally competent in practical matters}

When I left school, I embarked on the lengthy process of becoming a professionally qualified civil engineer. It involved paid work on construction sites, a 3-year degree course in engineering, and being indentured to a senior engineer for 2 years postgraduation. The degree course consisted of morning lectures and afternoons spent in the workshop or drawing office. In addition, during the 'vacations' we had to 
undertake various practical training courses. There was a general recognition that competence was developed both in the classroom and in practical arenas such as construction sites, factories and design offices. More generally, how professionals become competent was a major concern in the last century. Reviewing the history of professional development in the USA, Schön writes:

When, in the early decades of this century, the professions began to appropriate the prestige of the university by placing their schools within it, 'professionalization' meant the replacement of artistry by systematic, preferably scientific, knowledge. As awareness of the crisis of confidence in professional knowledge has grown, however, educators have begun once again to see artistry as an essential component of professional competence, to ask whether the professional schools can or should do anything about it and, if so, how can education for artistry can be made coherent with the professional curriculum's core of applied science and technique. (Schön 1987, p. 14).

The American philosopher John Dewey was an influential advocate of learning-bydoing (Dewey 1938a) and few professionals would deny that most, and probably the most important, learning occurs on the job. Schön $(1983,1987)$ articulates how the reflective practitioner gains competence in practice as does Kolb (1976, 1984), Argyris (1962, 1977), and Schein (1969, 1973, 1987). More recently competence development and diffusion have been theorized in terms of 'communities of practice' (Wenger et al. 2002).

\subsection{Becoming competent in OR}

These days most operational researchers start their career by obtaining an MSc on a course provided by the university department of mathematics or business. In terms of the OR competence model, mathematics departments tend to concentrate on 'conducting analysis', the left-hand leg in the competence schema (see Fig. 3). Business schools encourage students to start to 'appreciate the context', the righthand leg in the competence schema (see Fig. 3), by including courses on subjects such as accounting and finance, organisational behaviour, marketing and strategy. The central leg 'designing and managing process' has proved more difficult to address within the confines of a conventional course. Group work and class presentations are commonplace, but most weight, in the UK at least, is placed on an individual student project undertaken for a sponsoring company or organisation. Williams and Dickson (2000), reporting on the MSc at Strathclyde, emphasize the importance of integrating the technical, personal and commercial skills such that a postgraduate student is immediately effective as a practitioner (consultant). Scott (2002) suggests ways of stimulating greater awareness of approaches to learning both in students and in academics as facilitators of learning (see also Fellers 1996).

One approach to learning how to approach complex situations is by the use of cases studies (Kayes 2002). In the OR context, this has been examined by a number of authors (see for instance, Bell and von Lanzenauer 2000; Böcker 1987; Cochran 2000; Corner and Corner 2003; Williams and Dickson 2000). Case study teaching, first introduced in legal education to help students to 'think like a lawyer', has been 
widely adopted in business schools particularly for subjects such as organisational behaviour, marketing and strategy; cases can help the OR student understand what it means to think like a manager, an accountant or a strategist. But it is not easy to define exactly what is meant by 'think like an operational researcher'. This brings us back to the long running debate about whether OR can be defined by its techniques (in other words the left-hand leg of the schema) (Haley 1984). Boothroyd suggested that the defining feature of OR is the process (1978; see also Ormerod 2010a) in which case the quest to 'think like an operational researcher' needs to be rooted in the difficult-to-teach central leg of the schema concerned with process (see Fig. 3); the other two legs provide important but subsidiary support. Helping students to 'think like an operational researcher' comes down to help them develop appropriate mental models to aid reflection on what an OR contribution could be and what might be involved. PSMs draw attention to the design and management of the process of an intervention; learning to apply PSMs can be made to be central to the student's development of an understanding about the process of OR.

\subsection{Teaching PSMs in the classroom}

As 'soft OR' methods have gradually gained recognition, university lecturers have been struggling with the problem of how to introduce them into the curriculum. Which aspects can be addressed in the classroom? Which must be left until the student has the opportunity to use them in practice? At the same time, lecturers have to decide on the mode of teaching: traditional lectures; case study analysis and discussion; or some activity-based approach. However, lecturers have to be realistic as to what can be achieved when first exposing students to PSMs. Murphy comments:

A distinguishing feature of experts is the time they devote to the specific subject area in which they are interested. Simon and Chase (1973) note that it takes 10 years to become expert in chess. Ericsson and Crutcher (1990) find consistent support for the rule of thumb that it takes 10 years for someone to become an expert. Ericsson and Charness (1997) state that practice is not enough; structured learning and effortful adaptation are critical. To grow, those becoming experts must revisit what they did and understand their actions. (Murphy 2005b p. 313).

When I started teaching soft OR methods, there was little in the literature reporting on other lecturers' experiences. My expectations were not high, but I was surprised how much most students could pick up in a relatively short time. The challenge, as I saw it, was to engage the students so that they would get an idea of the features of some selected methods and get a general feel of different types of intervention so they could imagine why and when the methods might be useful; in other words I wanted them to develop mental models of what various soft methods could offer. I chose to concentrate on three methods: cognitive mapping, SSM and strategic choice analysis. Rather than lecturing the students about the methods, I facilitated various exercises to get the students engaged and to show by example what facilitation might involve. I made the learning experiences for each method as 
different as possible from the other two, partly for the practical reason that they seemed to lend themselves to different treatments; but more importantly, if nothing else, I wanted to leave them with vividly different memories (mental models) of each of the three methods.

For cognitive mapping (Eden 1988), the students produced maps of progressively more complex statements such that by the end of a 3-hour session they could extract a map from a lengthy unstructured text taken from interviews with senior managers. If they got stuck, I encouraged them to look at what their neighbour was doing. When they had finished, I got them to compare their map with that of their neighbour, and finally with my own version. From the final map, I encouraged them to pick out scenario assumptions, strategic actions, goals and so on, thus introducing them to the basis of the strategic options development and analysis (SODA) approach.

In the SSM (Checkland 1981) session I wanted to give them some experience of the collective creativity (and fun) of a free flowing session using a topic they would all know something about (usually the institution of marriage). I would always start by asking who would be involved, what they would be thinking about, and where the conflicts might lie (for instance, the mother of the bride, who should be invited; the vicar, the order of service; the best man, his speech). As they responded, I drew a rich picture on the board. From the shared rich picture thus created, a 'system' for further consideration was selected (for instance, the 'giving-of-presents system' that somehow brings together the expectations of the happy couple and the guests).

The SCA of Friend and Hickling (1987) proved something of a challenge given the structure and complexity of the process. I opted to take the example used by the originators in their book and 'walk' the students through it so that they could study the example further in the book if they wanted to. I took the idea of walking the students through the example literally, using poster-sized copies of the diagrams in the book stuck up on the walls round the lecture theatre. I walked the students round from one poster to another discussing, questioning and explaining the diagrams as we went. It involved a certain amount of jostling and climbing over desks, some students looking ahead to find out where it was going, others falling behind to discuss something they were not clear about.

A number of lecturers have reported on their teaching of soft methods; usually they advocate going into considerably more depth than I attempted; greater depth inevitably takes longer, making greater demands on an already full curriculum (Scott 1990). For instance, Hindle (2011) describes the difficulty that students from scientific backgrounds had when addressing messy problems in a participative, interpretative mode. Concluding that formal lectures are insufficient, he describes an extended student exercise designed to simulate a realistic engagement:

In groups of 3-4 students, the students are tasked with performing a consulting style project over a 1- to 2-month period for a client identified in the case study. The client is normally asking for a review of a complex situation or help in addressing a complex issue. The students' projects include at least four half hour meetings with the tutors. In the meetings, teaching staff will role-play actors such as the client, major stakeholders, or an SSM expert who works for 
the students' consulting firm - the students choose which character they want to talk to. The main objectives of the meetings are to give the groups a realistic project experience and also to facilitate all groups in reaching sensible analytic outputs (Hindle 2011, p. 38).

Ackermann, drawing on her experience of both teaching and working with soft methods in practice, highlights the following issues:

The challenges are composed of the following: helping students appreciate the implications of the sociopolitical world; giving students confidence, in not having to have the "right" answer; having to teach facilitation as well as the methods; providing students with an appreciation of the whole AND the details; helping students manage complexity, uncertainty, and holism; covering the material necessary within the time allocated; and teaching the class online. (Ackermann 2011, p. 56).

Mingers and Rosenhead, reviewing Ackermann's and other papers included in a special journal issue on teaching PSMs conclude: 'For each challenge, she [Ackermann] considers a number of options as to how they might be overcome. Many (but not all) of these involve somehow getting the real world into the classroom. That is an approach that all of the papers in this special issue support' (Mingers and Rosenhead 2011, p. 3). Underlying the different modes of teaching is the fundamental challenge of getting students to think about the nature of decisions, how people approach decision-making and how they interact with others involved in the process. What are the cognitive and political processes involved (Morley and Ormerod 1996)?

Andersen et al. (2006) report on an ambitious exercise aimed at advancing the teaching of the competences required to tackle strategic problems. Combining the experience of a number of researchers engaged in the development of strategy using SODA, systems dynamics and other techniques, the authors developed a complex model of the influences on strategy development and the management of change. An extended case study and modelling tools support the learning. We can note from this that it is not only students being introduced to PSMs that can benefit from facilitated learning, systems dynamics and other modelling techniques call on similar skills and can also be taught by bringing real-world problems into the class room.

\subsection{Competence development on the job}

Most commentators agree that the ideal theatre for developing competence in the use of PSMs is provided by practice itself. Skyrme (1997) points out that anyone using a methodology is in effect, using the results of the experience of others who have captured some of this experience in documentation. But, he says: 'As any newcomer to a methodology knows, this [the documentation] is only part of the knowledge needed to use it effectively. He or she will be sensitive to the working context, the personal biases of those providing the information and the needs of the various stakeholders' (Skyrme 1997, p. 220). 
Keys (2006) draws on Willemain $(1994,1995)$ noting the difference in the way that novices and experts set about traditional OR modelling. The novice can draw on the literature; the expert prefers to talk to the client and has a repository of experiences to draw on: "Novices might be expected to have a different type of knowledge and understanding of its application from experts and each novice has the potential to develop into a unique expert, in terms of the knowledge available to them and how they use it' (Keys 2006, p. 823). Keys suggests that such progress can be considered in terms of developmental stages from novice to expert:

A novice user of PSMs will be taken as someone who has no deep knowledge of the methods or how they are used but is aware of their existence and able to relate them with other management science methodologies they have used. An expert user, in contrast, will be taken to have knowledge that allows them to use some of the methods, reflect upon that use, and modify their practice. That is they will have knowledge and expertise that goes significantly beyond that gained by understanding a "textbook" description of a methodology. In between these categories lie two intermediate stages, apprentice and journeyman, that mark steps along the path from novice towards expert status. (Keys 2006, p. 825).

In terms of PSM competence, Keys emphasizes the analytical, social interaction and facilitating skills required:

Analysts must accept the need to work with those involved, for invariably it is not a single person, and to operate in a workshop situation as a facilitator rather than as a backroom technician. There are significant social actions that analysts are involved with as they implement and manage a process that will take a group forward. What makes PSMs distinct from other group facilitation approaches is the involvement of a model or representation. The analyst is responsible for introducing and gaining acceptance by the group for a modelbased engagement with the situation. Hence their actions involve a strong technical dimension related to the development and manipulation of a suitable representation. (Keys 2006, p. 824).

Bell and Morse (2013) emphasize the role of the facilitator in resolving tensions in the group. If group dynamics is poor, some members may opt out of the process leaving a sub-group or an individual to complete the task (p. 959). Group dynamics, facilitation and more generally personal skills are constantly occurring themes in the description of PSM interventions; usually these skills are intuitively understood. Bell and Morse raise the question as to whether they can be formalized. Very often facilitation skills are developed by observing how experienced facilitators conduct themselves: how they prepare; how they engage participants; how they animate the process and control it; how they encourage creativity and reflection; how they deal with challenges and crises; how they follow up. Once the plunge has been taken, learning involves doing and reflecting, perhaps with the help of some informal discussion or a brief questionnaire as a feedback mechanism.

Bryant has developed his theory of problem solving using the metaphor of drama (Bryant 1988, 1989, 1993, 1997). He emphasizes the sociological and psychological 
dynamics at play in an intervention both in terms of the individuals and groups of people involved (the actors) and the setting (the physical surrounding and props) in which the drama unfolds under the direction of the facilitator (impresario/director). Bryant suggests that the description of problem solving by Eden (1986) is a valuable tool, and when overlain with the real variability of interest, motivation, purpose, concern and intention within a group serves as a reliable guide to what may actually go on in a group context' (Bryant 1989, p. 98). Such an understanding of individual and group behaviour is clearly a necessary competence, whether informed by a guide or simply experience. Bryant also considers that an understanding of the effect of the setting is vital, a view also held by Eden (1985) and Hickling (1987).

\section{A new competence schema}

The OR competence model in Fig. 1 was conceived some time ago. The competence schema (see Fig. 3) informally elaborated the three core competences in the core competence model. The schema was based on the traditional OR approach and the limited number of papers conceptualizing the deployment of PSMs at that time. The subsequent PSM literature reviewed above provides a basis for reviewing and updating the schema. A summary of the literature review is provided in Table 2 in the form of a list of some of the key concepts. Some concepts overlap, some refer to outcomes rather than competences, while others are pitched at different levels of aggregation. In any synthesis, some overlapping has to be tolerated; outcomes can be reformulated as competences (for instance, 'ownership' can be recast as 'an ability to engender ownership'); levels of aggregation are addressed in the hierarchical design of the schema. Despite the variety of concepts in Table 2, some clear themes emerge.

\subsection{The three core competences revisited}

The identification of the three core competences, conducting analysis, designing and managing process, and appreciating context, is supported by the literature reviewed above, summarized in Table 2. Although it is perfectly possible to organize the competences in some other way, I see no need to change the existing structure of the competence model (see Fig. 1). However, the sub-categories in the schema (those indicated in Fig. 3) are clearly debatable. Each individual PSM contains in combination a notion (or rationale) of the process of intervention and some analytical techniques. This dual nature gives rise to a dilemma. The inclusion of process in the PSMs mean that they sit somewhat uneasily on the 'analysis' leg of the schema; the inclusion of analytical techniques means they sit equally uneasily on the 'process' leg. The simplest solution is to consider the analytical and process elements of each method to be separable and allocate them to the appropriate leg. I have in mind a conceptual rather than an actual unbundling. Each PSM can therefore be considered as consisting of a process to be enacted and the analytical techniques embedded in it. 
Table 2 Key concepts taken from the PSM literature reviewed

\begin{tabular}{|c|c|}
\hline Source & Key concepts \\
\hline \multicolumn{2}{|l|}{ Recruitment and survey data } \\
\hline GORS (2013) & Defining aims and objectives; problem structuring \\
\hline Sodhi \& Son (2010) & $\begin{array}{l}\text { Problem solving; communication; interpersonal skills; team-related } \\
\text { skills }\end{array}$ \\
\hline Liberatore \& Luo (2013) & $\begin{array}{l}\text { Problem formulation; problem recognition; communication; } \\
\text { business knowledge }\end{array}$ \\
\hline \multicolumn{2}{|l|}{ Evaluation research } \\
\hline White (2006) & $\begin{array}{l}\text { Participation; facilitation; formation of social networks; changes in } \\
\text { attitudes, adjustments to power relationships }\end{array}$ \\
\hline Franco (2007) & $\begin{array}{l}\text { Model and problem structure; accommodation of multiple } \\
\text { positions; shift in power relations; increased understanding and } \\
\text { learning; ownership of problem structure and of planned actions; } \\
\text { partial commitments }\end{array}$ \\
\hline Rouwette et al. (2009) & $\begin{array}{l}\text { Context; modelling; facilitation; communication; mental model } \\
\text { refinement; consensus; commitment; systems changes }\end{array}$ \\
\hline Champion \& Wilson (2010) & Systems builder competence; politics and personalities \\
\hline Bell and Morse (2013) & Group dynamics; facilitation \\
\hline Midgley et al. (2013) & Methods; context; purposes; outcomes \\
\hline \multicolumn{2}{|c|}{ Developing competence in the use of PSMs } \\
\hline Ackermann (2011) & $\begin{array}{l}\text { Appreciate the implications of the sociopolitical world; develop } \\
\text { confidence in not having the 'right' answers; facilitation; } \\
\text { methods; appreciate the whole and the details; manage } \\
\text { complexity, uncertainty and holism }\end{array}$ \\
\hline Andersen et al. (2006) & $\begin{array}{l}\text { Complex model; strategy development; management of change; } \\
\text { learning; facilitation }\end{array}$ \\
\hline Keys (2006) & $\begin{array}{l}\text { Analytical skills; social interaction skills; facilitating skills; } \\
\text { implementation and management of a process of social actions in } \\
\text { groups; use of models; development and manipulation of } \\
\text { representations }\end{array}$ \\
\hline Bryant (1989) & $\begin{array}{l}\text { Understanding of individual and group behaviour; group variability } \\
\text { of interest, motivation, purpose, concern, intension; group } \\
\text { context; group setting }\end{array}$ \\
\hline
\end{tabular}

The analytical elements of PSMs can happily sit alongside more conventional OR techniques in the 'conducting analysis' leg and need no further comment. However, the process elements help bring the 'designing and managing process' leg into sharper focus: clearly facilitation is a key activity in the use of PSMs. This focus on facilitation and the need for soft skills has led to a reappraisal of the way that more conventional methods are handled. Eden, Ackermann and collaborators (see for instance, Ackermann et al. 1997) have pursued the integration of cognitive mapping and system dynamics modelling. Robinson (2001) has advocated the use of soft approaches when developing simulation models. Von Winterfeldt and Fasolo (2009) note the increasing use of PSMs in conjunction with decision analysis; decision analysis in general, and multi-criteria decision analysis (MCDA) in particular, requires the deployment of soft skills and will frequently involve the facilitation of groups of participants and the use of PSMs (Belton et al. 1997; 
Montibeller et al. 2006; Montibeller and Belton 2006; Losa and Belton 2006). Franco and Montibeller (2010) have reviewed the concept of facilitated modelling.

The PSM literature considered here repeatedly emphasizes the third leg of the schema, 'appreciating context'. The context can be complex and demanding; for instance, the issue may involve multiple organizations (see for instance, Foote et al. 2007; Franco 2007). It can be argued that the sub-categories 'outer context' and 'inner context' are comprehensive, and indeed they are, but the review indicates that some further elaboration is justified. When addressing the 'outer context', traditional OR often (but by no means always) seeks to narrow down a problem to contribute some (usually quantitative) insight into the issues; PSMs emphasize widening the focus to reflect the inevitable openness of any organisational system. Thus, to make it clear that understanding the outer context includes social, economic, and political systems as well as the closer to home sector knowledge (energy, banking, health, local government, etc.), these aspects have been separated out in the new schema. Again, reflecting the literature review, the inner context can be usefully disaggregated into (1) organizations and functions (accounting, marketing, operations, information systems, human resources etc.) and (2) people and groups. I would interpret these headings broadly; for instance, organizational structure and networks, and organizational decision-making can be included in 'organizations and function'; group formation, personal ambition and power in 'people and groups'. Organizational roles and status, and ethos would be relevant in both sub-categories. The choice of these sub-categories and their content is, of course, debatable.

\subsection{Craft skills}

As has been noted the practice of OR is often referred to as a craft (see for instance, Majone 1984; Miser and Quade 1988; Willemain 1994, 1995) and other synonyms (for instance, art and expertise), reflecting the tacit knowledge of experienced practitioners (Polanyi 1967). Tacit knowledge enables consultants to take many decisions based on what they might think of as intuition, but it is in fact born mainly out of experience; such knowledge or knowhow is seldom codified but is nevertheless crucial in all aspects of an intervention. As Schön puts it:

In the terrain of professional practice, applied science and research-based technique occupy a critically important though limited territory, bounded on several sides by artistry. There are an art of problem framing, an art of implementation, and an art of improvisation-all necessary to mediate the use in practice of applied science and technique. (Schön 1987, p. 13).

Some level of irreducible element of artistry or craft skill needs to be recognized as present in all aspects of practice, in other words within all elements of the schema. What is 'irreducible' is continuously in need of redefinition as careful reflection on and codification of experience can demystify some activities. For instance, the development of 'scripts' seeks to codify some common activities in group modelling work (Andersen and Richardson 1997; Ackermann et al. 2011; Hovmand et al. 2012). 


\subsection{Mental models}

Another aspect that is apparent from the PSM literature is the need for mental models of the analytical methods, the process options and the contextual complexities. In order to design and manage the intervention process effectively, the consultant(s) needs to maintain a stock of these mental models; mental models help the consultant(s) envisage what can be achieved in a particular context, which analytical techniques could be used, and what sort of process is called for. Traditional OR has always relied implicitly on mental models, but the possibility of employing PSMs has widened the options and increased the complexity of intervention design; maintaining a stock of articulated mental models is now essential. In the schema, the simple mental models envisaged here could be considered as a necessary part of the 'process design' sub-category or they could be considered as three sub-categories, one for each core competence. Another possibility is to consider mental models to be part of 'craft skills'.

\subsection{OR and ethics}

Ethics is important in all OR but this is not always apparent (Ormerod and Ulrich 2013). However, PSMs are very often deployed when there is a lack of clarity about objectives (e.g. where multiple organizations are involved). In such situations ethical issues come to the fore. An appreciation of ethical issues is sufficiently important to justify its identification in the schema. One option is to have an allembracing category overarching the schema. The approach taken here is to break the subject down into four elements: personal and professional ethics; ethics in analysis; intervention ethics; and societal ethics.

\subsection{Commercial discipline}

Commercial considerations play a part in all choices from the initial design of the intervention to the withdrawal of consultants at the end of the project. Even a pro bono intervention has to be aware of the use of resources (the currency being peoples' time rather than money). Commercial considerations could be handled under ethics. In the revised schema, the presence of what can be called a 'commercial envelope' is acknowledged separately given its importance in practice.

\subsection{The revised OR competence schema}

In the light of the review of the PSM literature and the observations above, a revised OR competence schema shown in Fig. 4 is proposed. It is a proposal, a hypothesis to be amended, changed and elaborated. But primarily it is intended to be applied.

One recurring theme in the PSM literature reviewed here is the requirement to be a skilled facilitator (sub-competence: facilitation) and being able to recognize when it could be useful (sub-competence: mental models). More generally the competence, designing and managing the intervention process, is critical for all OR, traditional or soft. Facilitation is one distinguishing feature of PSMs. Modelling 


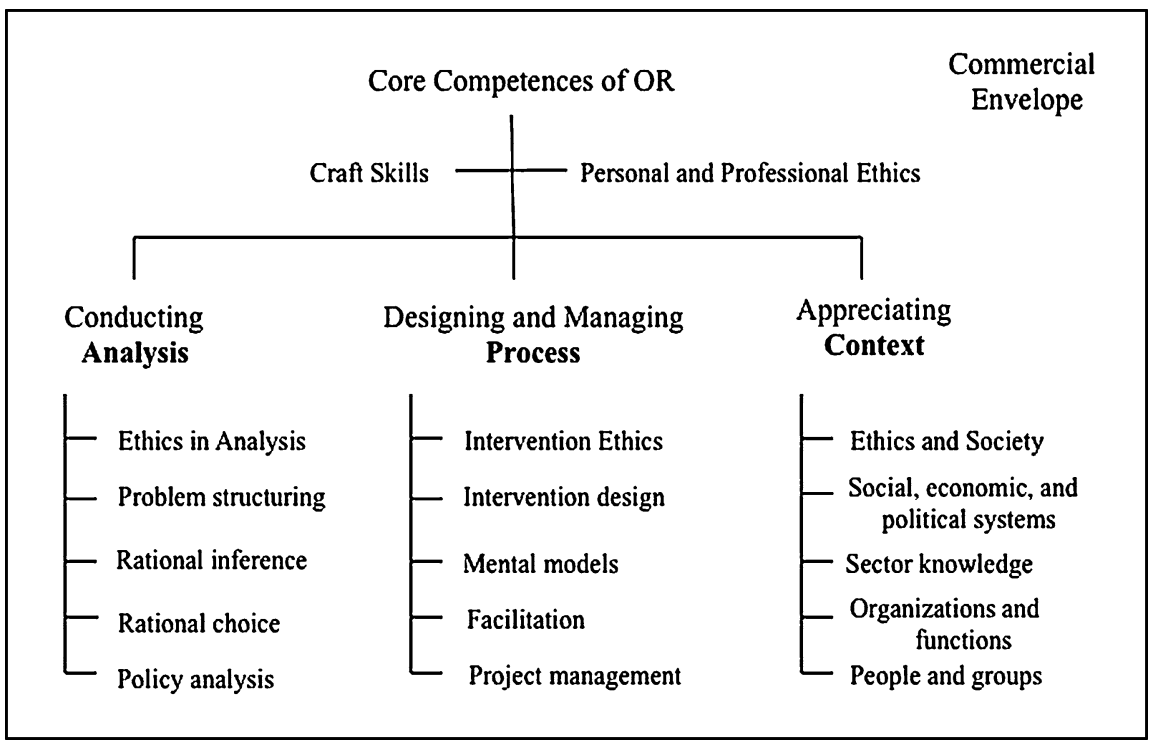

Fig. 4 The revised schema for the core competences of OR practice

(usually quantitative) is one of the distinguishing features of traditional OR. We have seen here that PSMs require mastery of new (often qualitative) analytical methods (sub-competence: problem structuring), and an increased emphasis on contextual understanding (competence: appreciating context) and ethical concerns (sub-competences: personal and professional ethics; ethics in analysis, intervention ethics, ethics and society). These new emphases are already having an impact on the way that more conventional approaches of traditional OR are conceived and understood. On the one hand, distinctions between traditional and soft/PSM approaches are apparent, while on the other the boundaries between the two are blurring.

\section{Application of the competence schema}

\subsection{The transformation competence perspective (TCP)}

The TCP is one of several approaches concerned with the design of an intervention processes (Ormerod 2008a). These can be collectively referred to as intervention design approaches (IDAs). Whereas Jackson's total systems intervention/creative holism chooses the approach according to the organizational metaphor adopted (Jackson 2003), Mingers' multimethodology looks to the philosophies underpinning the methods and Ulrich's critical systems heuristics is based on his theory of boundary choices, the TCP suggests that the design should primarily be based on finding an accommodation between a proposed transformation and the competences that can be dedicated to achieving it. In the TCP, it is suggested that an individual's 
competences should be summarized in terms of a personal intervention competence model (PICM). The OR revised competence schema derived above provides a basis for organizing PICMs.

Life can be breathed into the schema by looking at it from the TCP perspective. An intervention designed to achieve some chosen transformation is what Boothroyd refers to as an action programme (Boothroyd 1978; see also Ormerod 2010a). In terms of the schema, the activities of designing, facilitating and managing action programmes all lie on the central leg of the schema (see Fig. 4). The central leg can thus be seen as providing the animating force; drawing on mental models provided by all three legs, an intervention transformation is conceived and then made to happen. It is in the activities supported by the middle leg where the hard (and commercially speaking, sometimes hard-nosed) thinking has to take place to get the intervention on track in the first place and then to keep it there.

\subsection{Teaching OR competences}

Many university courses concentrate on the technical and mathematical content of OR; the development of competence in process and context is left to experience to be gained in practice. For those courses that have attempted to introduce some aspects of the process and context of practice, the challenge has been to overcome the inherent difficulty of simulating the conditions of practice and finding time within the conventional structure of courses. All this could change as it becomes increasingly obvious that, to maximize the value that can be delivered to students, advantage has to be taken of the advanced capabilities of technology and students' familiarity with its use. Clearly technical subjects no longer need to be taught in classrooms at a set time; they can be made available online to be accessed at the student's convenience. Face-to-face time will concentrate on some mixture of problem solving, simulation, group work and facilitated exercises. As the OR literature shows, this is a change already underway. The schema provides a framework for formulating the aims of a course and for curriculum design. It can also help students understand their educational experience and enable them to contribute to course content. We can anticipate a period of radical change (Jenlink 2001).

\subsection{Management of OR services}

Managers of OR services have to ensure the alignment of the competences of their consultants with current and future client needs. The development of a stock of competences within a group is a dynamic process involving recruitment, operational experience, and professional development activities. Clients' requirements also evolve dynamically as the issues they are confronted with change and as their understanding of the OR offer develops (see Fig. 5). The schema can help the managers of OR services think about new service offerings, the choice of assignments to pursue, the consequences of key consultants leaving, the requirements for recruiting, and the role of professional development. 


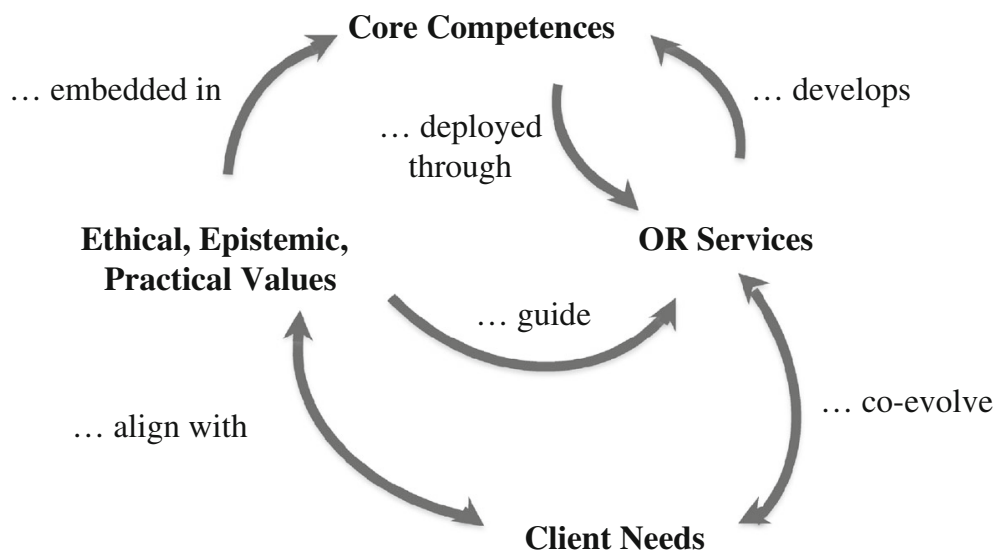

Fig. 5 The OR business model

\section{Delving deeper}

It could be argued that the characterization of traditional OR, PSMs, and competences given here is oversimplified. Not only is there a large body of research in other disciplines into the nature and psychology of intervention, participation and facilitation, a number of OR scholars have also been pursuing relevant questions. It is clear that much about the art or craft of practicing OR, that has in the past been considered too difficult and hidden to articulate, is now being formalized, giving rise to a better understanding of techniques, habits, and orientations. It can be anticipated that a number of subject areas (for instance, systems thinking, behavioural science, and sociological analysis) will provide the impetus for OR academics to seek a better understanding of OR competence. Concepts such as actor-networks, semantic nets, communities of practice, and group 'scripts' have the potential for further development and use and no doubt there are others. The theorizing will need to draw on empirical data from case studies, questionnaires, content analysis, interviews and focus groups. In this way, it should be possible to identify the changes in competence required as they emerge, providing a basis for updating the schema. What will remain constant is the imperative to maintain relevance in terms of client needs by the continuous development of relevant competences.

Acknowledgments The author would like to thank the editors of the special issue and the referees for their constructive comments.

\section{References}

Abbott A (1988) The system of professions: an essay on the division of expert labor. University of Chicago Press, Chicago

Ackermann F (1996) Participant's reflections on the role of facilitators using group decision support systems. Group Decis Negot 5:93-112 
Ackermann F (2011) Getting "messy" with problems: the challenges of teaching "soft" OR. INFORMS Trans Edu 12(1):55-64

Ackermann F, Eden C, Williams T (1997) Modeling for litigation: mixing qualitative and quantitative approaches. Interfaces 27(2):48-65

Ackermann F, Andersen DF, Eden C, Richardson GP (2011) SciptsMap: a tool for designing multimethod policy-making workshops. Omega 29:427-434

Ackoff RL (1974) Redesigning the Future. Wiley, New York

Ackoff RL (1979a) The future of operational research is past. J Oper Res Soc 30:93-104

Ackoff RL (1979b) Resurrecting the future of operational research. J Oper Res Soc 30:189-199

Andersen DF, Richardson GP (1997) Scripts for group model building. Syst Dyn Rev 13:107-129

Andersen DF, Bryson JM, Richardson GP, Fran Ackermann F, Eden C, Finn CB (2006) Integrating modes of systems thinking into strategic planning education and practice: the thinking persons' institute approach. J Public Aff Edu 12(3):265-293

Argyris C (1962) Interpersonal competence and organizational effectiveness. Dorsey Press, Homewood Argyris C (1977) Double loop learning in organizations. Harvard Business Review 115-125

Bell S, Morse S (2013) Groups and facilitators within problem structuring processes. J Oper Res Soc 64:959-972

Bell PC, von Lanzenauer CH (2000) Teaching objectives: the value of using cases in teaching operational research. J Oper Res Soc 51:1367-1377

Belton V, Ackermann F, Shepherd I (1997) Integrated support from problem structuring through to alternative evaluations using cope and V.I.S. J Multi-Criteria Decis Anal 6(3)115-130

Böcker F (1987) Is case teaching more effective than lecture teaching in business administration? An exploratory analysis. Interfaces 17(5):64-71

Boothroyd H (1978) Articulate intervention: the interface of science, mathematics and administration. Taylor and Francis, London

Bryant J (1988) Frameworks of inquiry: OR practice across the hard-soft divide. J Oper Res Soc 39:423-435

Bryant J (1989) Problem management: a guide for producers and players. Wiley, Chichester

Bryant J (1993) OR enactment: the theatrical metaphor as an analytical framework. J Oper Res Soc 44:551-561

Bryant J (1997) All the world's a stage. OR Insight 10(4):14-21

Champion D, Wilson JM (2010) The impact of contingency factors on the validation of problem structuring methods. J Oper Res Soc 61:1420-1431

Checkland PB (1981) Systems thinking, systems practice. Wiley, New York

Checkland PB (1985) From optimizing to learning: a development of systems thinking for the 1990s. J Oper Res Soc 36:757-767

Cochran JJ (2000) Introductory business OR cases: successful use of cases in introductory undergraduate business college operational research courses. J Oper Res Soc 51:1378-1385

Corbett CJ, Van Wassenhove LN (1993) The natural drift: what happened to operations research? Oper Res 41:625-640

Corner J, Corner PD (2003) Teaching OR/MS using discussion leadership. Interfaces 33(3):60-69

Dewey J (1938a) Experience and education. Kappa Delta Pi, New York. Currently available as a Simon \& Schuster Touchstone edition, first available 1997

Dewey J (1938b) Logic: the theory of inquiry. Holt, New York

Eden C (1985) Perish the thought. J Oper Res Soc 36:809-819

Eden C (1995) On evaluating the performance of 'wide-band' GDSS's. Eur J Oper Res 81:302-311

Eden C (1986) Problem solving or problem finishing? In: Jackson MC, Keys P (eds) New directions in management science. Gower Press, Aldershot

Eden C (1988) Cognitive mapping: a review. Eur J Oper Res 36:1-13

Eden C, Ackermann F (1996) 'Horses for courses': a stakeholder approach to the evaluation of GDSSs. Group Decis Negot 5:501-519

Eden C, Ackermann F (2000) Mapping distinctive competencies: a systemic approach. J Oper Res Soc 51:12-20

Eden C, Ackermann F (2006) Where next for problem structuring methods. J Oper Res Soc 57:766-768

Ericsson KA, Charness N, (1997) Cognitive and developmental factors in expert performance. In: Feltovich PJ, Ford KM, Hoffman RR (eds), Expertise in context. MIT Press, Cambridge, pp 3-41

Ericsson KA, Crutcher RJ (1990) The nature of exceptional performance. In: Baltes PB, Featherman DL, Lerner RM (eds) Life-span development and behavior, vol 10. Erlbaum, Hillsdale, pp 187-217 
Fellers JW (1996) People skills: using the cooperative learning model to teach students "people skills". Interfaces 26(5):42-49

Finlay P (1998) On evaluating the performance of GSS: furthering the debate. Eur J Oper Res 107:193-201

Foote JL, Gregor JE, Hepil MC, Baker VE, Houston DJ, Midgley G (2007) Systemic problem structuring applied to community involvement in water conservation. J Oper Res Soc 58:645-654

Franco LA (2007) Assessing the impact of problem structuring methods in multi-organizational settings: an empirical investigation. J Oper Res Soc 58:760-768

Franco LA, Montibeller G (2010) Facilitated modelling in operational research. Eur J Oper Res 205:489-500

Freidson E (1986) Professional powers: a study of the institutionalization of formal knowledge. University of Chicago Press, Chicago

Friend J, Hickling A (1987) Planning under Pressure. Pergamon, Oxford

Haley K (1984) Techniques maketh OR. J Oper Res Soc 35:191-194

Hickling A (1987) Putting decision management into context. Presented at: international symposium on decision management, Toronto

Hindle GA (2011) Teaching soft systems methodology and a blueprint for a module. INFORMS Trans Edu 12(1):31-40

Hovmand PS, Andersen DF, Rouwette EAJA, Richarardson GP, Rux K, Calhoun A (2012) Group modelbuilding 'scripts' as a collaborative planning tool. Syst Res Behavioural Sci 29:179-193

Jackson MC (2003) Systems thinking: creative holism for managers. Wiley, Chichester

Jackson MC, Keys P (1984) Towards a system of systems methodologies. J Oper Res Soc 35:473-486

Jenlink PM (2001) Designing educational systems for the twenty-first century. Syst Res Behavioral Sci 18(4):283-285

Kayes DC (2002) Experiential learning and its critics: preserving the role of experience in management learning and education. Acad Manag Learn Edu 1(2):137-149

Keys P (2006) On becoming expert in the use of problem structuring methods. J Oper Res Soc 57:822-829

Kolb D (1976) Management and the learning process. California Manag Rev 18(3):21-31

Kolb D (1984) Experiential learning: experience as the source of learning and development. PrenticeHall, New Jersey

Larson MS (1977) The rise of professionalism: a sociological analysis. University of California Press, Berkeley

Liberatore M, Luo W (2013) ASP, the art and science of practice: a comparison of technical and soft skill requirements for analytics and OR professionals. Interfaces 43(2):194-197

Losa FB, Belton V (2006) Combining MCDA and conflict analysis: an exploratory application of an integrated approach. J Oper Res Soc 57:510-525

Majone G (1984) The craft of applied systems analysis. In: Tomlinson RC, Kiss I (eds) Rethinking the process of operational research \& systems analysis. Pergamon, Oxford, pp 143-158

Midgley G, Cavana RY, Brocklesby J, Foot JL, Wood DRR, Ahuriri-Driscoll A (2013) Towards a new framework for evaluating systemic problem structuring methods. Eur J Oper Res 229:143-154

Mingers J (1997) Multi-paradigm multimethodology. In: Mingers J, Gill A, Multimethodology: the theory and practice of combining management science methodologies. Wiley, Chichester

Mingers J, Rosenhead J (2011) Introduction to the special issue: teaching soft O.R., problem structuring methods and multimethodology. INFORMS Trans Edu 12(1):1-3

Mingers J, White L (2010) A review of the recent contribution of systems thinking to operational research and management science. Eur J Oper Res 207:1147-1161

Miser HJ, Quade ES (1988) Introduction: craftsmanship in analysis. In: Miser HJ, Quade ES (eds) Handbook of systems analysis: craft issues and procedural choices. Wiley, Chichester, pp 1-26

Mitchell GH (1993) The practice of operational research. Wiley, Chichester

Montibeller G, Belton V (2006) Causal maps and the evaluation of decision options-a review. J Oper Res Soc 57:779-791

Montibeller G, Shaw D, Westcombe M (2006) Using decision support systems to facilitate the social process of knowledge management. Knowl Manag Res Prac 4:125-137

Morley IE, Ormerod RJ (1996) A language-action approach to operational research. J Oper Res Soc 47:731-740

Murphy F (2001) The practice of operations research and the role of practice and practitioners in INFORMS. Interfaces 31(6):98-111 
Murphy FH (2005a) ASP, the art and science of practice: elements of a theory of the practice of operations research: a framework. Interfaces 35(2):154-163

Murphy FH (2005b) ASP, the art and science of practice: elements of a theory of the practice of operations research: expertise in practice. Interfaces 35(4):313-322

Murphy FH (2005c) ASP, the art and science of practice: elements of a theory of the practice of operations research: practice as a business. Interfaces 35(6):524-530

Ormerod RJ (1983) Corporate planning and its use of O.R. in the N.C.B.: a personal view. J Oper Res Soc 34:461-467

Ormerod RJ (1995) Putting soft OR methods to work: information systems strategy development at Sainsbury's. J Oper Res Soc 46:277-293

Ormerod RJ (1996a) Information systems strategy development at Sainsbury's Supermarkets using soft OR. Interfaces 26(1):102-130

Ormerod RJ (1996b) Putting soft OR methods to work-information systems strategy development at Richards Bay. J Oper Res Soc 47:1083-1097

Ormerod RJ (1997a) Mixing methods in practice: a transformation-competence perspective. In: Mingers J, Gill A (eds) Multimethodology: the theory and practice of integrating methodologies. Wiley, Chichester, pp 29-58

Ormerod RJ (1997b) The design of organisational intervention: choosing the approach. Omega 25:415-513

Ormerod RJ (1997c) The role of OR in shaping the future: smart bits, helpful ways, and things that matter. J Oper Res Soc 48:1045-1056

Ormerod RJ (1998a) Putting soft OR methods to work-information systems strategy development at Palabora. Omega 26:75-98

Ormerod RJ (1998b) Beyond internal OR groups. J Oper Res Soc 49:420-429

Ormerod RJ (1999) Putting soft OR methods to work-business improvement at PowerGen. Eur J Oper Res 118:1-29

Ormerod RJ (2001a) Mixing methods in practice. In: Rosenhead J, Mingers J (eds) Rational analysis for a problematic world revisited: problem structuring methods for complexity, uncertainty and conflict. Wiley, Chichester, pp 311-336

Ormerod RJ (2001b) The success and failure of methodologies - a comment on Connell 2001: evaluating soft OR. J Oper Res Soc 52:1176-1179

Ormerod RJ (2002) On the nature of OR: taking stock. J Oper Res Soc 53:475-491

Ormerod RJ (2005) Putting soft OR to work: the case of IS strategy development for the UK Parliament. J Oper Res Soc 56:1379-1398

Ormerod RJ (2006) The history and ideas of pragmatism. J Oper Res Soc 57:892-909

Ormerod RJ (2008a) The transformation competence perspective. J Oper Res Soc 59:1435-1448

Ormerod RJ (2008b) The history and ideas of Marxism: the relevance for OR. J Oper Res Soc 59:1573-1590

Ormerod RJ (2010a) Articulate intervention revisited. J Oper Res Soc 61:1078-1094

Ormerod RJ (2010b) Rational Inference: deductive, inductive and probabilistic thinking. J Oper Res Soc 61:1207-1223

Ormerod RJ (2010c) Justifying the methods of OR. J Oper Res Soc 61:1694-1708

Ormerod RJ (2010d) OR as rational choice: a decision and game theory perspective. J Oper Res Soc 61:1761-1776

Ormerod RJ, Ulrich W (2013) Ethics and OR: a literature review. Eur J Oper Res 228:291-307

Parsons T (1939) The professions and social structure. Social forces, 17:457-467. Reprinted in Parsons T (1954). Essays in social theory, rev. ed. (orig. 1949), Free Press, New York, pp 34-49

Parsons T (1952) A sociologist looks at the legal profession. Conference on the professions of law and legal education, University of Chicago, Chicago pp 49-63. Reprinted in Parsons T (1954) Essays in social theory, rev. ed. (orig. 1949), Free Press, New York, pp 370-85

Pauley GS, Ormerod RJ (1998) The evolution of a performance measurement project at RTZ. Interfaces 28(4):94-118

Phillips L, Phillips MC (1993) Facilitated work groups: theory and practice. J Oper Res Soc 44:533-549

Polanyi M (1967) The tacit dimension. Doubleday, New York

Prahalad CK, Hamel G (1990) The core competence of the organisation. Harvard Bus Rev, 79-91

Quinn RE, Rohrbaugh J (1983) A spatial model of effectiveness criteria: towards a competing values approach to organisational analysis. Manage Sci 29(3):363-377

Rittel HWJ, Webber MM (1973) Dilemmas in general theory of planning. Policy Sci 4:155-169 
Robinson S (2001) Soft with a hard centre: discrete-event simulation in facilitation. J Oper Res Soc 52:905-915

Rosenhead J (ed) (1989) Rational analysis for a problematic world: problem structuring methods for complexity, uncertainty and conflict. Wiley, Chichester

Rosenhead J (1996) What's the problem? An introduction to problem structuring methods. Interfaces 26(6):117-131

Rosenhead J, Mingers J (eds) (2001) Rational analysis for a problematic world revisited. Problem structuring methods for complexity, uncertainty and conflict. Wiley, Chichester

Rouwette EAJA (2011) Facilitated modeling in strategy development: measuring the impact on communication, consensus and commitment. J Oper Res Soc 62:879-887

Rouwette EAJA, Vennix JAM, Felling AJA (2009) On evaluating the performance of problem structuring methods: an attempt at formulating a conceptual model. Group Decis Negot 18:567-587

Schein EH (1969) Process Consultation. Addison Wesley, Boston

Schein EH (1973) Professional education. McGraw-Hill, New York

Schein EH (1987) The clinical perspective in fieldwork. Sage, Newbury Park

Schön DA (1983) The reflective practitioner. Basic Books, New York

Schön DA (1987b) Educating the reflective practitioner: towards a new design for teaching and learning in the professions. Jossey-Bass, San Francisco

Scott JL (1990) OR methodology and the learning cycle. Omega 18:551-553

Scott JL (2002) Stimulating awareness of actual learning processes. J Oper Res Soc 53:2-10

Simon HA, Chase WG (1973) Skill in chess. Am Sci 61(4):394-403

Skyrme DJ (1997) Multimethodologies-the knowledge perspective. In: Mingers J, Gill A (eds) Multimethodology. Wiley, Chichester, pp 217-240

Sodhi M, Son B (2010) Content analysis of OR job advertisements to infer required skills. J Oper Res Soc 61:1315-1327

UK Government Operational Research Service (GORS), 2013. Competences needed for OR. http://www. operational-research.gov.uk/recruitment/competencies/ Accessed on 5 Feb 2013

Ulrich W (1994) Critical heuristics of social planning: a new approach to practical philosophy. Wiley, Chichester

Ulrich W (2001) The quest for competence in systemic research and practice. Syst Res Behavioral Sci 18:3-28

Ulrich W (2011a) What is good professional practice? (part 1: introduction). Ulrich's Bimonthly, MarchApril. http://wulrich.com/bimonthly_march2011.html

Ulrich W (2011b) What is good professional practice? (part 2: the quest for practical reason). Ulrich's Bimonthly, May-June. http://wulrich.com/bimonthly_may2011.html

Ulrich W (2012) What is good professional practice? (part 3: the quest for rational action). Ulrich's Bimonthly, May-June. http://wulrich.com/bimonthly_may2012.html

von Winterfeldt D, Fasolo B (2009) Structuring decision problems: a case study and reflections for practitioners. Eur J Oper Res 199:857-866

Wenger E, McDermott R, Snyder WM (2002) Cultivating communities of practice: a guide to managing knowledge. Harvard Business School Press, Boston

Westcombe M, Franco LA, Shaw D (2006) Where next for PSMs-A grassroots revolution? J Oper Res Soc 57:776-778

White LA (2006) Evaluating problem-structuring methods: developing an approach to show the value and effectiveness of PSMs. J Oper Res Soc 57:842-855

Willemain TR (1994) Insights on modelling from a dozen experts. Oper Res 42:213-222

Willemain TR (1995) Model formulation: what experts think about and when. Oper Res 43:916-932

Williams T, Dickson K (2000) Teaching real-life OR to MSc students. J Oper Res Soc 51:1440-1448

Woolley RN, Pidd M (1981) Problem structuring-a literature review. J Oper Res Soc 32:197-206 